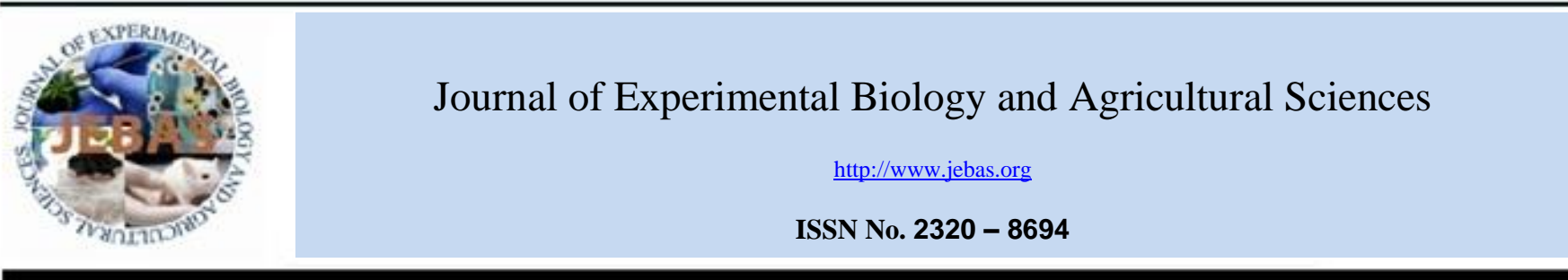

\title{
PHENOLICS AND ASCORBIC CONTENTS IN TWO SAGE (Salvia sps. L) SPECIES
}

\section{Estella Bimenyindavyi (iD), Olga Arnoldovna Timofeeva (iD)}

Department of Botany and Plant Physiology, the Institute of Fundamental Medicine and Biology, Kazan Federal University, Kazan, Russia

Received - September 25, 2020; Revision - November 16, 2020; Accepted - December 14, 2020

Available Online December 15, 2020

DOI: http://dx.doi.org/ 10.18006/2020.8(Spl-2-AABAS).S286.S291

\section{KEYWORDS}

Soluble Phenolic Compounds

Ascorbic Acid

Lilac Sage

Dry-Steppe Sage

Tatarstan

Crimea

\begin{abstract}
This work was carried out for the quantitative estimation of phenolic compounds (soluble phenolic compounds, flavonoids such as quercetin, cynaroside, and avicularin) and ascorbic acid level in the aerial plant parts (leaves and stems) of two sage species viz., Salvia tesquicola (dry-steppe sage) and Salvia verticillata (lilac sage) grown in Tatarstan and Crimea, Kazan, Russia respectively. The highest content of phenolic compounds and the ascorbic acid level was reported in the leaves, while the value of these chemical constitutes was lowest in the stems of both species. Further, it has been shown, that these plants are rich in all investigated chemicals but among these Cynaroside and avicularin are the predominated flavonoids (cynaroside, quercetin, and avicularin). The amount of all studied active compounds differed significantly and it depends on the plant organs, species, and place of growth. Further, the results of the study revealed that the content of soluble phenolic compounds in sage plants did not depend on the species and place of growth while the growing conditions had a greater impact on the amount of flavonoids and vitamin $\mathrm{C}$ contents.
\end{abstract}

* Corresponding author

E-mail: otimofeeva2008@mail.ru (Olga Arnoldovna Timofeeva)

Peer review under responsibility of Journal of Experimental Biology and Agricultural Sciences.

Production and Hosting by Horizon Publisher India [HPI] (http://www.horizonpublisherindia.in/).

All rights reserved.
All the articles published by Journal of Experimental Biology and Agricultural Sciences are licensed under a Creative Commons Attribution-NonCommercial 4.0 International License Based on a work at www.jebas.org.

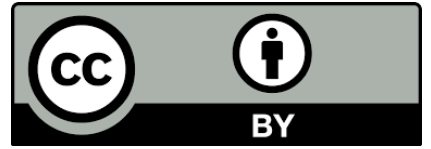




\section{Introduction}

Oil Medicinal plants have numerous biologically active substances as well as mineral elements which can be used in various fields such as medicine, food, pharmaceutical, and cosmetology industry (Khadanovich \& Pyrkh, 2018). These bioactive substances have various specific properties such as antioxidant, anti-inflammatory, antibiotic, antiviral, antiulcerogenic action, normalize cardiovascular system, and also exhibit enzymatic and hormonal activities (Omarieva, 2011; Frolova et al., 2016). These biologically active substances do not only differ in their physical and chemical properties but also differ in their physiological action (Hilali et al., 2020; Khandelwal \& Choudhary, 2020).

The main biologically active substances present in various medicinal plants include flavonoids, tannins, vitamins, coumarins, phenol carboxylic acids, anthocyanins, alkaloids, essential oils, etc. According to the previous literature, phenolic compounds and ascorbic acid are powerful antioxidants and invariably protect the body from chronic diseases, removing numerous different reactive oxygen species, including hydroxyl radical, peroxyl radical hypochlorous acids, superoxide anion, and peroxynitrite (Sviridenko et al., 2012; Brilkina et al., 2014). There are also evidences in the literature that suggests that the accumulation of reactive oxygen species in the body caused an imbalance between the pro-and antioxidant systems which plays an important role in the occurrence of severe chronic diseases, such as cardiovascular, cancer, diabetes, arthritis, etc. (Vardanyan et al., 2013). These biologically active substances in various medicinal plants will provide high-quality raw materials to the pharmaceutical industry which can be widely used for therapeutic purposes.

Dry-steppe sage (Salvia tesquicola) is used in folk medicine as an astringent, anti-inflammatory, and antimicrobial remedy (Shmygareva et al., 2017). Although it is not included in the official list of pharmacopoeial plants of the Russian Federation as garden sage (Salvia officinalis), but nevertheless, it is recommended to be used for the treatment of several diseases. According to Nemereshina \& Gusev, (2019), the phytochemical composition of dry-steppe sage includes essential oils, diterpene acids, flavonoids, tannins, vitamin $\mathrm{C}$, phenol carboxylic acids, carotenoids, and tocopherol. Further, Lilac sage (Salvia verticillata) is a honey plant and its phytochemical composition is similar to other sage species but the content of biologically active substances is lower than in Salvia officinalis (Bubenchikova \& Kondratova, 2008). Lilac sage plant is also used in folk medicine as a wound healing and expectorant remedy, for the treatment of enuresis, diarrhea in children, furuncles, and disinfection of the oral cavity. Some studies also show the antigen toxic effect of methanol extracts of Lilac sage (Erbil \& Digrak, 2015).
Various previous studies have established that the richness of the phytochemical composition of medicinal plants largely depends on the specific ecological and geographical conditions. This study aimed to determine the level of the accumulation of different phenolic compounds and ascorbic acid in two sage species i.e. drysteppe sage (Salvia tesquicola) and lilac sage (Salvia verticillata), growing in the territory of Tatarstan and Crimea.

\section{Materials and Methods}

Healthy plants of both species (Salvia tesquicola and Salvia verticillata) were harvested in 2018 at the flowering stage and were shaded dried under laboratory conditions. For the phytochemical analysis, leaves and stems were separated and ground to a powdery state. This powder material was used to prepare extracts.

To determine the total soluble phenolic compounds, $1.5 \mathrm{ml}$ of distilled water was added to $50 \mathrm{mg}$ of dried powder, and then samples are placed on a water bath at $70^{\circ} \mathrm{C}$ for 45 minutes. The mixture was centrifuged at $15000 \mathrm{Xg}$ for 5 minutes. The supernatant was collected, and the extractions were repeated twice. This extract solution was analyzed as a soluble phenolic extract ( $\mathrm{Li}$ et al.2018). The content of ascorbic acid was determined using potassium hexacyanoferrate as per the method given by Sibgatullina et al. (2011). While the flavonoids contents were determined concerning absorption to avicularin, cynaroside (Andreeva \& Kalinkina, 2000), and quercetin (Fedoseeva et al., 2009).

\section{Results and Discussion}

Phenolic compounds are the largest group of molecules, which included various types of aromatic secondary plant metabolites. According to Gulsunoglua et al. (2019), these phenolic compounds are the most common in plants and are classified into insoluble compounds (such as tannins, lignins) and soluble compounds (such as phenolic acids, phenylpropanoids, flavonoids, and quinones).

The results of the quantitative analysis of water-soluble phenolic compounds available in analyzed samples are shown in Figure 1. The content of phenolic compounds varied with plant species and used plant parts (Stem or leaves). The level of total phenolic contents ranged from 41.56 to $43.9 \mathrm{mg} / \mathrm{g}$ in leaves dry matter and it was reported from 35.66 to $40 \mathrm{mg} / \mathrm{g}$ in stems dry matter. In the case of total water-soluble phenolic compounds, leaves show superiority over the stem but among the studied two species no significant differences were found. Nevertheless, there was a tendency to an increase in the amount of phenolic compounds in $S$. verticillata plants, collected in Crimea, compared with plants of the same species, collected in Tatarstan. 


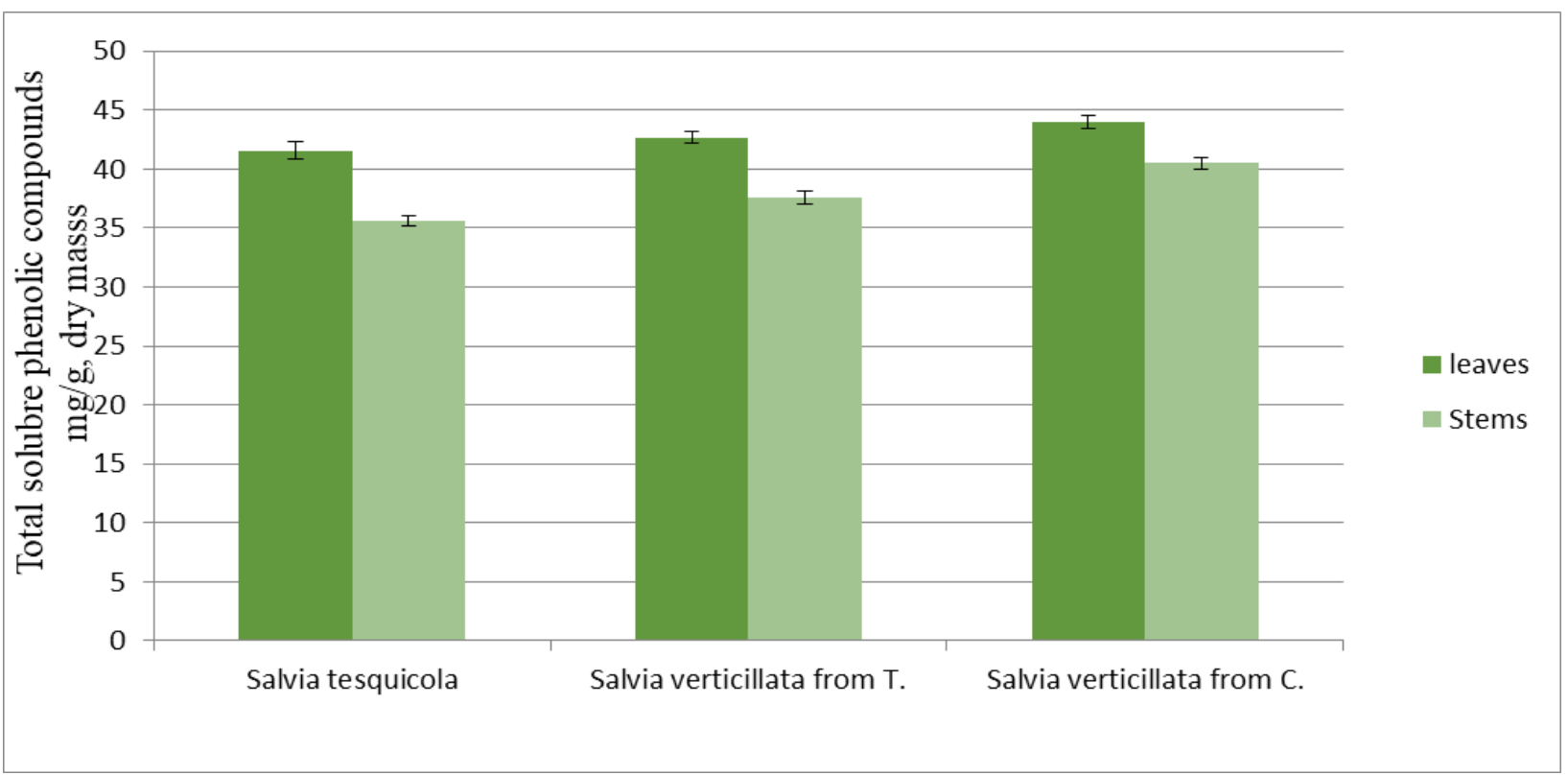

Figure1 Total soluble phenolic compounds in Salvia tesquicola and Salvia verticillata from Tatarstan (T) and Crimea (C)

Flavonoids are composed of various classes of compounds such as anthocyanins, isoflavonoids, flavones, flavonols, chalcones, aurones, and catechins (Wang \& Shun, 2018). Flavonoids have wide importance in the field of medicine and pharmacology (Kurkin \&Avdeeva, 2013). The results related to flavonoids are shown in Figure 2, 3, and 4, the most important class of flavonoids which reported from both the Sage species are quercetin, cynaroside, and avicularin. Results of the study revealed that leaves have higher flavonoids content as compared to the stems. The level of flavonoids content in sage leaves varies, among the reported flavonoids, quercetin range from $0.57-0.72 \%$, avicularin range from $5.29-7.52 \%$, and cynaroside range from $6.92-10.02 \%$. While in the case of stem, the content of quercetin was 0.12 $0.16 \%$, avicularin- $1.06-1.42 \%$, and cynaroside $-1.3-1.35 \%$, and this is lower than the flavonoids reported in the leaves. A further effect of geographical location and type of species did not affect the level of flavonoids content and both species are significantly at par. Cynaroside and avicularin are the prevail flavonoids of sage plants and these are maximum reported in $S$. verticillata, growing in Crimea (Figure 3 and 4).

Among these, Quercetin is the most studied flavonoid and has antioxidant, anti-inflammatory, antihypertensive, vasodilating, antihypercholesterolemic, and antiatherosclerotic effects; it also counteracts obesity (Delnavazi et al., 2015; David et al., 2016; Kurepa et al., 2019). Avicularin (quercetin-3-a-L-arabinofuranoside) is a quercetin glycoside, which has anti-inflammatory, antiallergic, antioxidant, hepatoprotective, and antitumor activities (Lee et al., 2019; Wang et al., 2019). A flavonoid-like compound, cynaroside, is a flavones which is also known as luteolin-7-O-glucoside, has antioxidant and anti-inflammatory action (Zoua et al., 2018; Szekalska et al., 2020).

It is generally known that secondary metabolites, in particular, phenolic compounds have protective functions in plants and their synthesis is largely determined by environmental conditions. The wide spectrum of anti-stress activity of phenolic compounds is primarily associated with the antioxidant properties of these molecules and their ability to absorb free radicals and reduce peroxidation of cell membranes. The protective role of these phenols in drought conditions is also well reported. Sharma et al. (2019) suggested that these phenolic compounds can protect plants from excess radiation by absorbing visible light (anthocyanins) and ultraviolet light (anthocyanins and colorless flavonoids). It has been proven that plants, growing at high altitudes, accumulate more phenolic compounds than plants in the temperate zone. The geographic and climatic conditions of Crimea are characterized by high sunniness with little precipitation. These factors are decisive in the accumulation of phenolic compounds in sage plants.

The amount of ascorbic acid in the analyzed samples is shown in Figure 5. Ascorbic acid is the most important antioxidant involved in the reduction of the oxidized form of vitamin $\mathrm{E}$ that facilitates the penetration of this vitamin through cell membranes (Agadzhanyan \& Agadzhanyan, 2012). The content of ascorbic acid is ranged from $402.8-513.6 \mu \mathrm{kg} / \mathrm{g}$ in leaves, and 203-243.2 $\mu \mathrm{g} / \mathrm{g}$ in stems. The highest level of vitamin $\mathrm{C}$ was found in the leaves of $S$. verticillata growing in Crimea. 


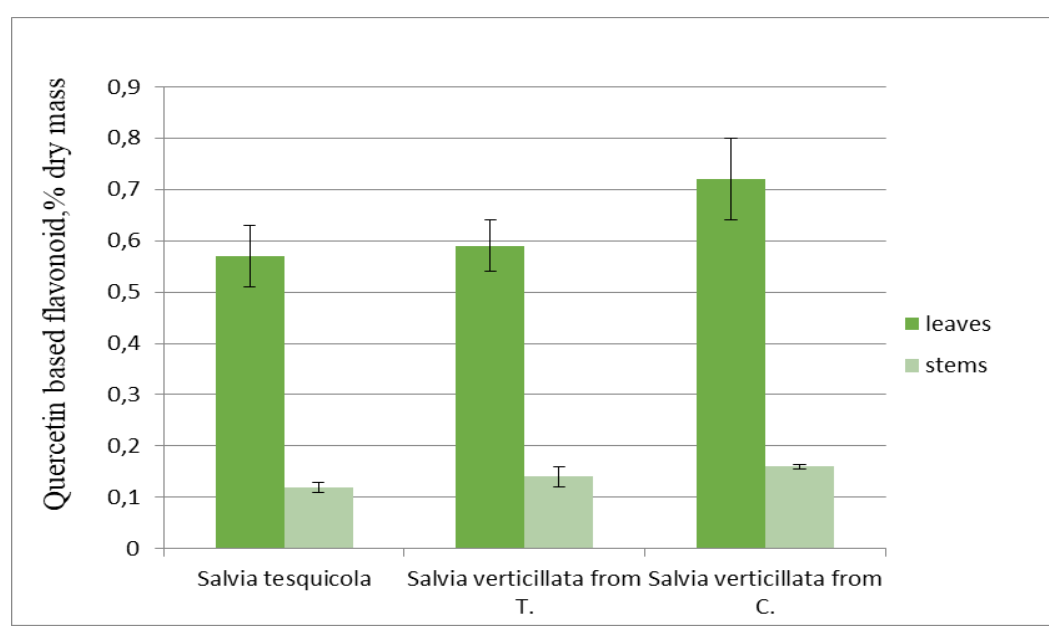

Figure 2 Quercetin based flavonoids in S. tesquicola and S. verticillata from Tatarstan (T) and Crimea $(\mathrm{C})$

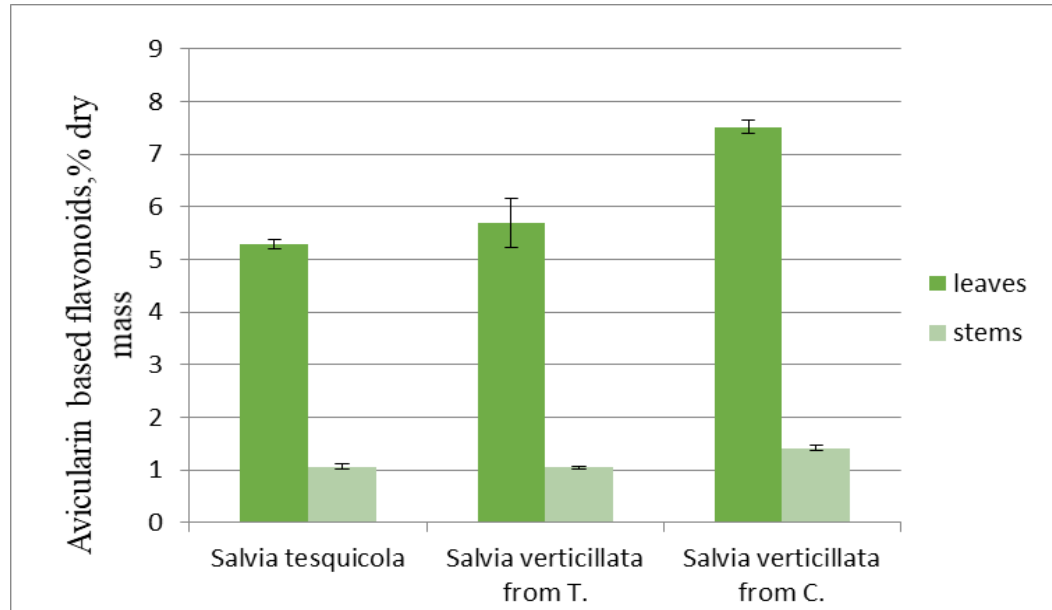

Figure 3 Avicularin based flavonoids in S. tesquicola and S. verticillata from Tatarstan (T) and Crimea $(\mathrm{C})$

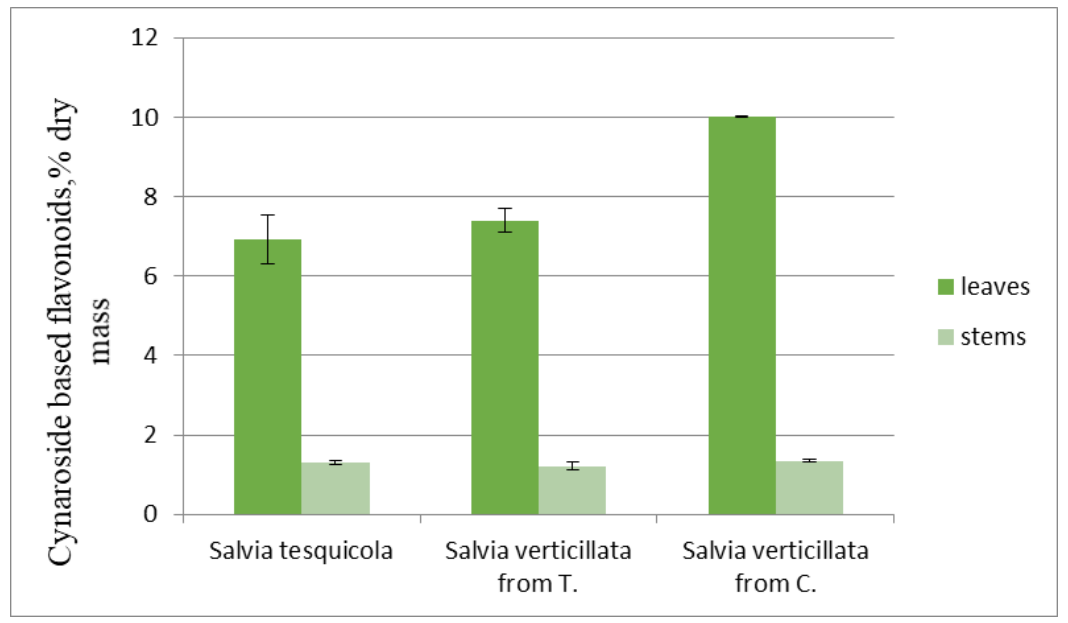

Figure 4 Cynaroside based flavonoids in S. tesquicola and S. verticillata from Tatarstan (T) and Crimea $(\mathrm{C})$
Ascorbic acid (vitamin C) is contained in almost exclusively in green plants and, as a rule, it is absent in chlorophyll-free forms. Conditions, favorable for photosynthesis, promote the accumulation of ascorbic acid. As mentioned above, the geographical conditions of Crimea are characterized by high sunniness, which is favorable for photosynthesis and synthesis of ascorbic acid. Further, it was reported that lilac sage and dry-steppe sage grown in Tatarstan did not differ in the content of ascorbic acid because the climatic condition of this area is not so warm.

\section{Conclusion}

Results of this research revealed uneven distribution of bioactive substances in lilac sage and dry-steppe sage grown in Tatarstan and Crimea, and this difference is mainly dependent on the type of plant parts used for extraction and geographical locations. Further, the high content of the studied phytochemical components was observed in leaves, while the stems contain fewer amounts of these biologically active substances. Certain dependence of these bioactive substances with the place of growth was also revealed such as sage plants, collected in Crimea, were characterized by a higher content of the studied substances, than the plants collected from the territory of Tatarstan. Similarly, seasonality, amount of thermal and light energy, amount of precipitation, and environmental humidity also have some impact on the phytochemical composition of sage. A detailed study related to the dependence of accumulation of biologically active substances with the place of plant growth is an urgent need to establish the results of the current study.

\section{Acknowledgements}

The work is performed according to the Russian Government Program of Competitive Growth of Kazan Federal University. This work was carried out with the financial support of the Russian Foundation for Basic Research and the Government of the Republic of Tatarstan in the framework of the scientific project No. 18-44-160015.

Journal of Experimental Biology and Agricultural Sciences http://www.jebas.org 


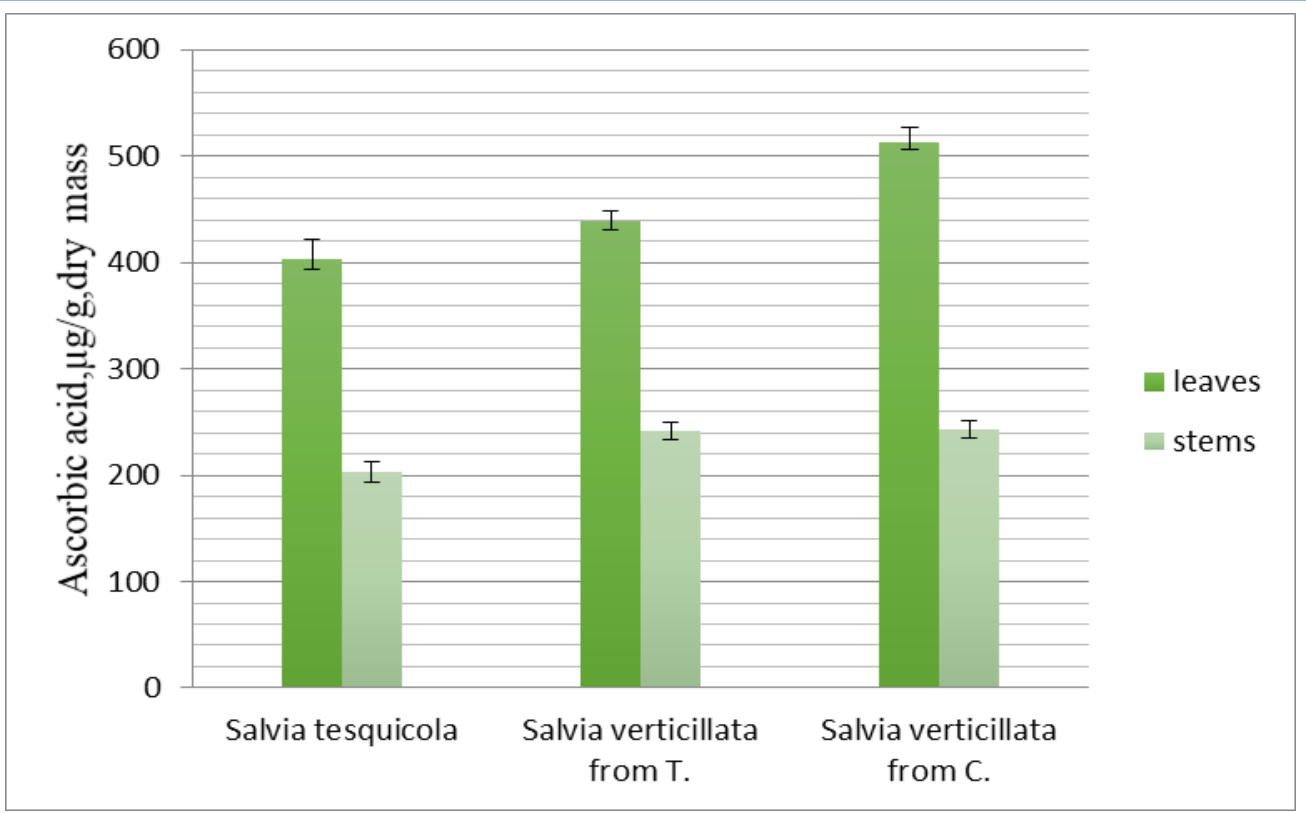

Figure 5 Content of ascorbic acid in S. tesquicola and S. verticillata from Tatarstan (T) and Crimea (C)

\section{Conflict of Interest}

Authors would hereby like to declare that there is no conflict of interests that could possibly arise.

\section{References}

Agadzhanyan AK, Agadzhanyan AA (2012) Antioxidant properties of some medicinal plants. Biological Journal of Armenia 4(64): 76-79.

Andreeva VY, Kalinkina GI (2000) Development of the method for quantitative determination of flavonoids in common lady'smantle Alchemilla vulgaris 1.s.l. Chemistry of Plant Raw Materials 1: 85-88.

Brilkina AA, Ageeva MN, Berezina EV, Pavlova EE, Mishukova IV (2014) The features of accumulation of phenolic compounds in leaves and berries of some representatives of the genus vaccinium from the collection of Scientific Research Institute Botanical garden of Nizhny Novgorod State University. Vestnik of Lobachevsky University of Nizhni Novgorod 3(3): 30-34.

Bubenchikova VN, Kondratova YuA (2008) The study of the polysaccharide and mineral composition of the herb Sage verticillata 1. Chemistry of Plant Raw Materials 3: 185-186.

David AV, Arulmoli R, Parasuraman S (2016) Overviews of biological importance of quercetin: A Bioactive flavonoid. Pharmacognosy Reviews 10(20): 384-389.
Delnavazi MR, Shahabi M, Yassa N (2015) Flavonoids from the leaves of Iranian Linden; Tiliarubra subsp. Caucasica. Research Journal of Pharmacognosy (RJP) 2(3): 17-22.

Erbil N, Digrak M (2015) Total phenolic and flavonoid contents, antimicrobial and antioxidant properties of Salvia verticillata $\mathrm{L}$. var. amasiaca and Salvia microstegia Boiss\&Bal from Turkish Flora. Journal of Microbiology and Antimicrobial Agents 1(1): 23-29.

Fedoseeva GM, Mirovich VM, Goryachkina EG, Perelomova MV (2009) Phytochemical analysis of plant raw materials containing flavonoids. Resource Book, Irkutsk, Pp. 67.

Frolova OO, Kompantseva EV, Dementyeva TM (2016) Biologically active substances of plants of the genus Willow (Salix L.). Pharmacy \& Pharmacology 42 : $41-$ 59. DOI: https://doi.org/10.19163/2307-9266-2016-4-2(15)-41-59.

Gulsunoglua Z, Gulera FK, Raesb K Akyilmaz MIK (2019) Soluble and insoluble-bound phenolics and antioxidant activity of various industrial plant wastes. International Journal of Food Properties 22(1): 1501-1510.

Hilali M, El Monfalouti H, Kartah BE (2020) Evaluation of the chemical composition of Argan (Arganiaspinosa L.) oil according to its extraction method,origin of production and altitude. Online Journal of Animal and Feed Research 10(3): 111--118.

Khadanovich AV, Pyrkh, OV (2018) The analysis of the content of ascorbic acid and zinc in medicinal plants. Scientific look into the future 3(11): 89-91. 
Khandelwal V, Choudhary PK (2020) Antioxidant and anticancer potential of Neolamarckia cadamba (ROXB.) bark extract. Journal of Experimental Biology and Agricultural Sciences 8: 334-338.

Kurepa J, Shull TE, Smalle JA (2019) Quercetin feeding protects plants against oxidative stress. F1000Research 6(5): 2430.

Kurkin VA, Avdeeva EV (2013) Flavonoids as biologically active compounds of medicinal plants. Fundamental Research 11: 1897-1901.

Lee JS, Lee AY, Quilantang NG, Geraldino PJL, Cho EJ, Lee S (2019) Anti-oxidant activity of avicularin and isovitexin from Lespedeza cuneata. Journal of Applied Biological Chemistry 62(2): 143-147.

Li Q, Yang S, Li Y, Xue X, Huang Y, Luo H, Zhang Y, Lu Z (2018) Comparative Evaluation of Soluble and Insoluble-Bound Phenolics and Antioxidant Activity of Two Chinese Mistletoes. Molecules 23: 359. doi:10.3390/molecules23020359

Nemereshina ON, Gusev NF (2019) Dry-steppe sage as a promising medicinal plant in the steppe zone of Russia. Izvestiya of the Orenburg State Agrarian University 6(80): 118-121.

Omarieva LV (2011) The influence of environmental factors on the accumulation of biologically active substances in fruits of Crataegus pentagyna waldst et kit in the conditions of Dagestan. South of Russia: Dcology, Development 4: 28-31.

Sharma A, Shahzad B, Rehman A, Bhardwaj R, Landi M, Zheng B (2019) Response of phenylpropanoid pathway and the role of polyphenols in plants under abiotic stress. Molecules 24(13):2452. doi: 10.3390/molecules24132452.

Shmygareva AA, Kurkin VA, Sankov AN, Nikandrova MA (2017) The actual aspects of analysis of medicinal plants, growing on the territory of Orenburg region. International Journal of Pharmacognosy and Phytochemical Research 9(5): 640-642.

Sibgatullina GV, Khaertdinova LR, Gumerova EA, Akulov AN, Kostyukova AY, Nikonorova AN, Rumyantseva IN (2011) The methods for determining the redox status of cultured plant cells. Study guide, Kazan: Kazan (Volga) Federal University: 36-45.

Sviridenko VG, Khadanovich AV, Lysenkova AV, Filippova VA (2012) Accumulation of microelements and ascorbic acid in medicinal plants. Problems of Health and Ecology 3-33: 137-142.

Szekalska M, Sosnowska K, Kowa MT, Winnicka K, Kasacka I, Tomczykd M (2020) In vivo anti-inflammatory and anti-allergic activities of cynaroside evaluated by using hydrogel formulations. Biomedicine \& Pharmacotherapy 121(1096813):1-13. doi: 10.1016/j.biopha.2019.109681.

Vardanyan RL, Atabekyan LV, Grigoryan GS (2013) Study of the antioxidant properties of medicinal plants in the Goris region of Armenia. Chemistry of Plant Raw Materials 1: 151-156,.

Wang TY, Shun QL (2018) Bioactive flavonoids in medicinal plants: Structure, activity and biological fate. Asian Journal of Pharmaceutical Sciences 13:12-23.

Wang Z, Li F, Quan Y, Shen J (2019) Avicularin ameliorates human hepatocellular carcinoma via the regulation of NF- $\kappa$ B/COX-2/PPAR- $\gamma$ activities. Molecular Medicine Reports 19(6): 5417-5423.

Zoua Y, Zhanga M, Zhanga T, Wua J, Wangb J, Liua K, Zhanc N (2018) Antioxidant and anti-inflammatory activities of cynaroside from Elsholtizabodinieri. Natural Product Communications 13(11):1501-1504. 